\title{
NEW POSTGRADUATE DENTAL EDUCATION CENTRE ANNOUNCED
}

NHS Manchester Primary Care Trust and the University of Manchester's School of Dentistry are jointly commissioning a new primary care-based Postgraduate Dental Education Centre (PgDEC).

The Centre, based in Lovell House, Hulme, close to the University campus, will provide routine NHS dental access, accept referrals from dentists within Manchester and provide support or advice on provision of complex primary care dentistry.

The PgDEC will enable the University's School of Dentistry to expand and provide training in a primary care setting within the local community, while supporting the NHS aim to increase access to dental services.
Clinical teaching will take place in the Centre, built with the latest equipment and facilities to provide excellent standards of training and patient care.

The service specification provides the requirements for provision of a high quality mandatory and preventive NHS primary dental care service. The overall aims for the service are to increase access and achieve sustained improvements in oral health and NHS dentistry. There will be an emphasis on endodontic and periodontal treatments, as these treatment modalities are especially suited to a primary care setting. A smaller amount of prosthodontic and oral surgery activity is anticipated.

\section{NEW CHILDREN'S GUIDANCE}

The Scottish Dental Clinical Effectiveness Programme (SDCEP) has published new guidance on the prevention and management of dental caries in children.

It aims to support primary care practitioners and their teams in improving and maintaining the oral health of patients up to the age of 16 and provides advice on patient assessment, delivery of preventive care based on caries risk, caries management, restorative care, recall and referral, and the management of dental neglect.

A summary version and a range of other resources to promote implementation of the guidance are also available, including illustrated step-by-step advice on clinical techniques and care checklists. The guidance can be accessed at www.sdcep.org. uk; follow the link to 'Dental Caries in Children' under 'Published Guidance'.

\section{STUDENT PRIZE LAUNCHED AT DUNDEE}

A new student prize is to be established in the School of Dentistry at the University of Dundee thanks to the generosity of an alumni group.

The St Andrews Dental Alumni consists of those dentists who graduated from the School either before 1967 - when what is now the University of Dundee was Queen's College, Dundee, part of the University of St Andrews or in the few years after when students were free to choose to graduate from either Dundee or St Andrews.

Following a number of reunions in recent years, many of them to celebrate 40, 50 and even 60 year graduation anniversaries, it was decided to raise a fund for a student prize.

'We wanted to do something to mark our appreciation of the training and help we received in our time at what was then Queen's College, Dundee, and also to honour the heritage of the St Andrews dental graduates,' said Professor Sir David Mason, one of the alumni group.

'As the students of the past, we were

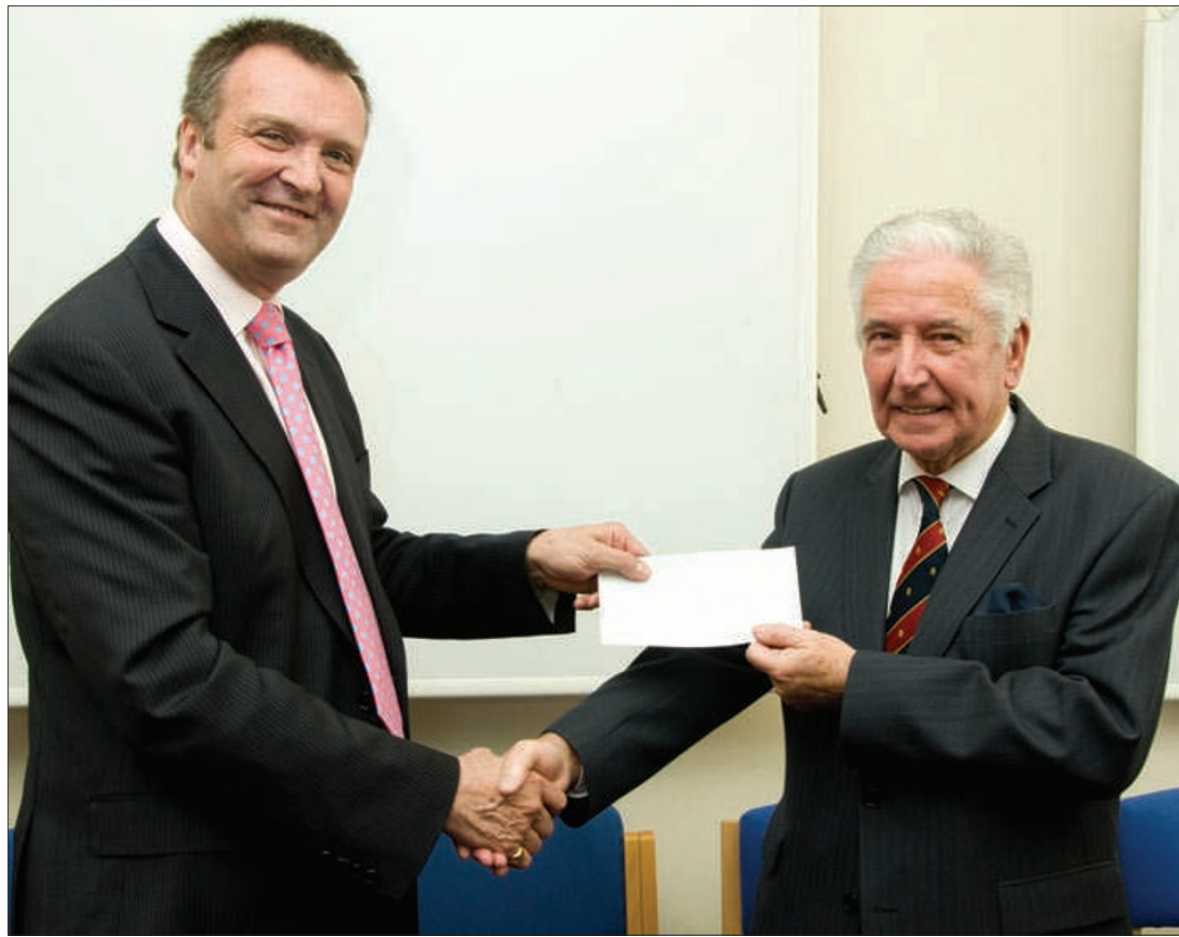

Left to right, Professor William Saunders, Dean of the School of Dentistry, receiving the cheque from Professor Sir David Mason

very keen to give some help to the students of the future. There are around 150 alumni we have been in contact with and the response has been very good. We have collected over $£ 17,000$ now which we will be donating to the University to fund a student prize.'

The details of what the prize will consist of and how it will be awarded are still being discussed in the School of Dentistry but it is anticipated it may fund student research projects. 